\title{
Teaching Photonics
}

\author{
Katarzyna A. Rutkowska* and Mirosław A. Karpierz \\ Faculty of Physics, Warsaw University of Technology, Koszykowa 75, 00-662 Warszawa,
}

Received September 30, 2017; accepted September 30, 2017; published September 30, 2017

There is a need to teach modern photonics as a tool for technology of the 21st century. Apart from the studies in Applied Physics, the Faculty of Physics at the Warsaw University of Technology (WUT) offers a program in English which leads to the M.Sc. degree in Photonics. The two-year graduate program in the area of Photonics provides students with a unique opportunity to become familiar with the applications of light in fields that range from fundamental research to technological applications. The aim of this Master's Program is to provide engineers and scientists with solid basic knowledge in the field of photonics and skills to apply this knowledge to design, production and management of photonic systems for a broad range of application domains.

Graduates from this degree program will acquire specialist knowledge in mathematics, physics, electronics, and information technology and have high level qualifications useful in various institutions. During their studies they may learn both theory and practice, while following the core photonic courses like Electromagnetism Theory, Principles of Optics, Fourier Optics and Nonlinear Optics, as well as Optical Imaging Theory. The Faculty offers also advanced and specialized courses in optics and photonics covering all relevant fundamental research and applications including training in lasers, optical and photonic crystal fibers, liquid crystal photonics, optical waveguides, displays, holography, optoelectronics, optical sensing, data and telecommunication, terahertz technology, new material technology, ultra-fast and nonlinear optical phenomena, photovoltaics. Advanced laboratories are also provided. A two-week professional internship is mandatory for all students in Photonics and has to be thematically related to their field of studies.
The teaching program in Photonics is conducted in cooperation with other faculties at WUT (including e.g. Faculty of Electronics and Information Technology, and Faculty of Mechatronics) and with research institutes, giving students access to a broad and complementary range of photonics expertise, design software, as well as fabrication and characterization facilities. Such cooperation is of high value for both students and industry partners, especially in regards to future employment. It is worth noting that the Master theses in Photonics are often realized in relation to scientific projects in various research laboratories.

This September, the first graduates in Photonics passed their final exams, defended their thesis and obtained M.Sc. Eng. degree in Photonics. Selected results of their work have been published in the current issue of the Photonics Letters of Poland.

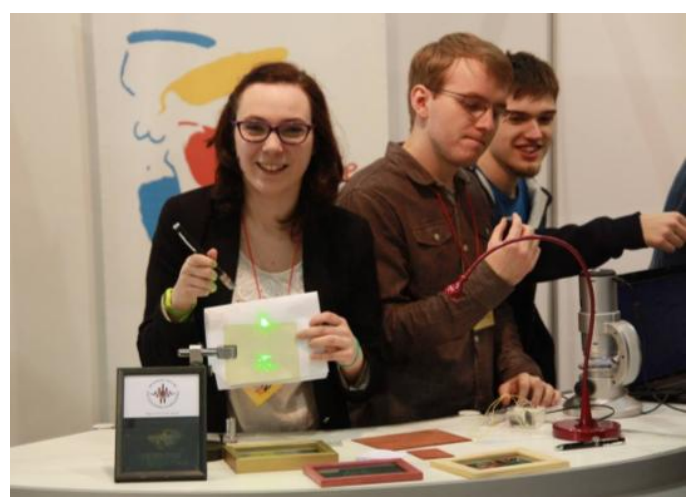

Fig. 1. Students from the Optics and Photonics Student Club actively participated in the International Fair for Optoelectronics and Photonics OPTON Expo 2015.

*E-mail: kasia@if.pw.edu.pl 